\title{
An alcohol oxidase biosensor using PNR redox mediator at carbon film electrodes
}

\author{
Madalina M. Barsan, Christopher M.A. Brett* \\ Departamento de Química, Universidade de Coimbra, 3004-535 Coimbra, Portugal
}

Received 30 May 2007; received in revised form 27 September 2007; accepted 28 September 2007

Available online 2 October 2007

\begin{abstract}
A new amperometric biosensor for ethanol monitoring has been developed and optimised. The biosensor uses poly(neutral red) (PNR), as redox mediator, which is electropolymerised on carbon film electrodes and alcohol oxidase (AlcOx) from Hansenula polymorpha as recognition element, immobilised by cross-linking with glutaraldehyde (GA) in the presence of bovine serum albumin (BSA) as carrier protein. Optimisation of variables affecting the system was performed and, for chronoamperometric measurements, a potential of $-0.300 \mathrm{~V}$ versus saturated calomel electrode was chosen in $0.1 \mathrm{M}$ sodium phosphate buffer saline at $\mathrm{pH}$ 7.5. The optimised biosensor showed a good sensitivity of $171.8 \pm 14.8 \mathrm{nAmM} \mathrm{m}^{-1}$ and the corresponding detection limit (signal-to-noise-ratio $=3$ ) of $29.7 \pm 1.5 \mu \mathrm{M}$. Stability studies showed a good preservation of the bioanalytical properties of the sensor, $57.6 \%$ of its initial sensitivity remaining after 3 weeks (the sensor was used two to three times per week). No significant interferences were found from compounds usually present in wine. The biosensor was used for the determination of ethanol in Portuguese red and white wines.
\end{abstract}

(C) 2007 Elsevier B.V. All rights reserved.

Keywords: Alcohol oxidase; Electrochemical enzyme biosensor; Poly(neutral red); Ethanol determination

\section{Introduction}

The determination of ethanol is important in food technology, fermentation and wine industries as well as in clinical chemistry: blood, serum and urine analysis. It is thus of much interest to develop fast and accurate procedures for ethanol determination. A variety of methods and strategies for the determination of this analyte has been reported, including gas chromatography [1], liquid chromatography with biosensor detection [2], refractometry [3] and spectrophotometry, both based on NADH detection. These methods, routinely used in industry, are slow, relatively expensive and need well-trained operators. Biosensors are versatile analytical tools, offering an attractive alternative for ethanol determination. For this purpose, a large variety of different biosensors have been proposed, using mainly alcohol oxidase (AlcOx) [4-6], $\mathrm{NAD}^{+}$-dependent alcohol dehydrogenase (AlcDh) [7-9] or PQQ-containing alcohol dehydrogenase [10].

\footnotetext{
* Corresponding author. Tel.: +351 239 835295; fax: +351 239835295 . E-mail address: brett@ci.uc.pt (C.M.A. Brett).
}

Alcohol oxidase is the key enzyme for methanol metabolism in metylotrophic yeast species, including Pichia pastoris, Hansenula polymorpha and Candida boidinii. The enzyme catalyses the first step of methanol catabolism, namely its oxidation to formaldehyde with concomitant production of hydrogen peroxide. In vivo, the protein is compartmentalized into special cell organelles, termed peroxisomes [11]. It is a homooctameric flavoprotein consisting of eight identical subunits, each containing flavin adenine dinucleotide (FAD) as a prosthetic group [12]. Considering this, alcohol oxidase-based biosensors have an advantage when compared with those that use alcohol dehydrogenase as biorecognition element, because the latter need the cofactor to be added to the sample or to be immobilised on the sensor surface. Since AlcOx enzyme enzymatically converts all primary alcohols and formaldehyde [13] it exhibits a lack of selectivity to ethanol. However, this should not be a problem in the use of such a biosensor for analysis of ethanol in natural samples such as wine, since ethanol is present in much higher concentrations. The main problem of AlcOx-based biosensors is their limited stability. For this reason, Gibson et al. conducted several stabilisation studies of AlcOx in the dry state using a combination of polyelectrolytes and sugar derivatives [14-16]. 
In this work the development of a novel AlcOx biosensor based on carbon film electrodes made from electrical resistors is reported [17], these electrodes having been previously characterized for use in electroanalysis $[18,19]$. In previous work, carbon film electrodes were used as substrates for various biosensor assembly constructions, using as redox mediators ferrocene, hexacyanoferrates and polymerized phenazine dyes [20-27]. In the latter case, the biosensor assembly was prepared by immobilising the enzyme by cross-linking with glutaraldehyde in the presence of bovine serum albumin on the top of poly(neutral red) (PNR) modified carbon film electrodes. Neutral red was found to be a convenient artificial enzyme substrate and has been recently used as a starting material for the preparation of electropolymerised films of PNR that can function as redox mediators in biosensors [20]. The chemical structure of NR, with an amino functionality located on heteroaromatic phenazine ring, makes it amenable to electropolymerisation. The monomer can be polymerized from neutral aqueous solutions producing stable redox-active layers [28,29]. The main advantage of this new biosensor is the fact that PNR can mediate the enzymatic reaction catalyzed by AlcOx, since a lot of previous attempts to mediate this enzyme have failed [5-8]. It is well known that AlcOx is incompatible with most freediffusing mediators, which makes it extremely difficult to design electron-transfer pathways between the redox active centre of the enzyme (the enzymatic cofactor) and the electrode, at low potentials. In addition, the active site of the enzyme is deeply buried within the octameric protein shell, preventing any direct electron transfer in the absence of a suitable redox mediator [30].

Optimisation of experimental conditions has been carried out and the analytical parameters for the determination of ethanol determined for several biosensor assemblies, which contain different amounts of immobilised enzyme. The operational and storage stability of the biosensor were also evaluated.

\section{Experimental}

\subsection{Reagents}

Alcohol oxidase (AlcOx, EC 1.1.3.13, 7.7 units/mg solid extracted from methylotrophic yeast Hansenula sp.), glutaraldehyde (GA) 25\% (v/v), bovine serum albumin (BSA), L-ascorbic acid and DL-lactic acid were from Sigma, Germany. Ethanol, methanol, 2-propanol, DL-malic acid and citric acid monohydrate were obtained from Merck, Germany. Neutral red (65\% dye content) and sodium phosphate monobasic monohydrate were from Sigma-Aldrich, Germany. Di-sodium hydrogenphosphate-2-hydrate, potassium hydrogenphosphate, sodium chloride and acetic acid were from Riedel-de Haën, Germany. Di-potassium hydrogenphosphate-3-hydrate was from Panreac, Spain. Potassium chloride and oxalic acid was from Fluka, Switzerland and tartaric acid was from JMUP, Portugal.

For electrochemical experiments, the supporting electrolyte was sodium phosphate buffer saline (NaPBS) $(0.1 \mathrm{M}$ phosphate buffer $+0.05 \mathrm{M} \mathrm{NaCl}$ and $\mathrm{pH} 6.0,6.5,7.0,7.5$ and 8.0). Polymerisation of neutral red was carried out in an electrolyte composed of $0.025 \mathrm{M}$ potassium phosphate buffer solution and $0.1 \mathrm{M} \mathrm{KNO}_{3}$ (pH 5.5).

Millipore Milli-Q nanopure water (resistivity $>18 \mathrm{M} \Omega \mathrm{cm}$ ) was used for preparation of all solutions. Experiments were performed at room temperature $\left(25 \pm 1{ }^{\circ} \mathrm{C}\right)$.

\subsection{Apparatus}

Batch experiments were performed in a three-electrode electrochemical cell of volume $10 \mathrm{~cm}^{3}$, containing the enzyme modified carbon film resistor as working electrode, a platinum foil counter electrode and a saturated calomel electrode (SCE) as reference.

All electrochemical measurements were performed using a computer-controlled $\mu$-Autolab Type II potentiostatgalvanostat running with general purpose electrochemical system (GPES) for Windows Version 4.9 software (EcoChemie, Utrecht, The Netherlands).

The $\mathrm{pH}$ measurements were carried out with a CRISON 2001 micro-pH meter at room temperature.

\subsection{Electrode and mediator film preparation}

Carbon film cylindrical electrodes were made from carbon film electrical resistors ( $2 \Omega$ resistance) of length $6 \mathrm{~mm}$ and diameter $1.5 \mathrm{~mm}$, as described elsewhere [18]. The exposed geometric area was $\sim 0.20 \mathrm{~cm}^{2}$. Before use, the electrodes were electrochemically pre-treated by cycling the potential between $0.0 \mathrm{~V}$ and $+1.0 \mathrm{~V}$ versus SCE in $0.025 \mathrm{M}$ potassium phosphate buffer solution, $\mathrm{pH} 5.5$, in order to decrease the background currents and to increase the potential window.

The preparation of poly(neutral red) films was carried out by cyclic voltammetry from a solution containing $1 \mathrm{mM}$ monomer dye in $0.025 \mathrm{M} \mathrm{KPB}+0.1 \mathrm{M} \mathrm{KNO}_{3}$, pH 5.5. The potential was cycled from -1.0 to $1.0 \mathrm{~V}$ versus SCE at a scan rate of $50 \mathrm{mV} \mathrm{s}^{-1}$ for 15 cycles [24-26].

Alcohol oxidase was immobilised using cross-linking with glutaraldehyde (GA). Three different enzyme solutions were prepared, by mixing the enzyme together with BSA in $0.1 \mathrm{M}$ NaPBS, pH 7.0 and the concentrations were: $1 \%$ AlcOx $+4 \%$ $\mathrm{BSA}, 3 \% \mathrm{AlcOx}+4 \% \mathrm{BSA}$ and $5 \% \mathrm{AlcOx}+10 \% \mathrm{BSA}$. A volume of $10 \mu \mathrm{l}$ of enzyme solution was then mixed with $5 \mu \mathrm{l} \mathrm{GA}$ $(2.5 \%, \mathrm{v} / \mathrm{v}$ diluted in water). Of this mixture, $10 \mu \mathrm{l}$ was dropped onto the electrode surface and left to dry at room temperature during $1 \mathrm{~h}$.

All biosensors were tested in a batch cell. Amperometric measurements were performed at fixed potential, after stabilisation of the current baseline, with injection of alcohol into $0.1 \mathrm{M}$ NaPBS solution in which the biosensor was immersed. Experiments were done under continuous stirring conditions.

\section{Results and discussion}

\subsection{Optimisation of the PNR/AlcOx biosensor}

The optimisation of variables affecting the AlcOx-based biosensor system, prepared as described in Section 2, was per- 


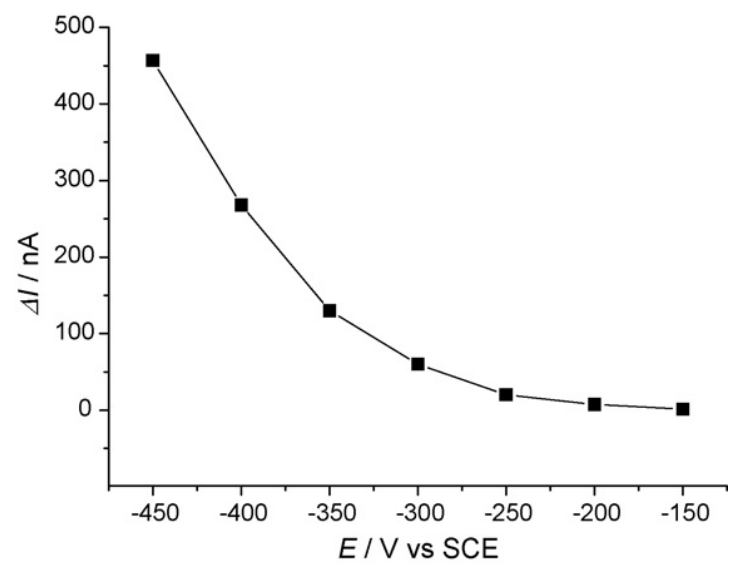

Fig. 1. Dependence of PNR/AlcOx biosensor response on applied potential; measurements performed in $0.1 \mathrm{M} \mathrm{NaPBS}$ and $\mathrm{pH}$ 7.0.

formed with respect to applied potential and with respect to buffer $\mathrm{pH}$.

The effect of applied potential on the amperometric response of the PNR/AlcOx modified electrode as a function of alcohol concentration was studied using an enzyme solution containing 5\% AlcOx and 10\% BSA for biosensor construction. Experiments were done by injection of $0.40 \mathrm{mM}$ ethanol after baseline stabilisation for each applied potential. The results obtained are presented in Fig. 1 and show that at, all applied potentials, oxidation processes occur at the electrode. This can be explained by a direct electronic communication between PNR and the enzyme cofactor, flavine adenine dinucleotide, so that the reduced form of the redox active prosthetic group of the AlcOx $\left(\mathrm{FADH}_{2}\right)$, which is formed during the enzymatic oxidation of ethanol, is then reoxidized at the PNR film. In this way, at the electrode, the PNR mediator will be oxidized and the registered biosensor response is an anodic change in current. The proposed mechanism is presented in Scheme 1a. At $-0.45 \mathrm{~V}$ and $-0.40 \mathrm{~V}$ versus SCE, potentials closer to the formal potential of the FAD/FADH 2 couple $\left(E_{\mathrm{FAD} / \mathrm{FADH}_{2}}^{0^{\prime}} \cong-0.45 \mathrm{~V}\right.$ vs. SCE$)$, the biosensor response is much higher when compared with that recorded at more positive applied potentials. At these potentials, it is clear that the energetics of the redox processes is facilitated. Nevertheless, a potential of $-0.30 \mathrm{~V}$ was selected as working potential for subsequent studies with the aim of minimising possible interferences.

In order to prove that PNR acts as electron acceptor from $\mathrm{FADH}_{2}$, chronoamperometry was performed at a PNR/AlcOx biosensor at $-0.3 \mathrm{~V}$ versus SCE, in deoxygenated buffer with injection of deoxygenated ethanol solution, after the same biosensor had been previously tested in the presence of oxygen. The biosensor characteristics were compared, and in the absence of oxygen the biosensor sensitivity increased by $21.6 \%$. This means that PNR replaces $\mathrm{O}_{2}$ as the electron shuttle. Low oxygen solubility in aqueous solutions and the difficulty associated with controlling the $\mathrm{O}_{2}$ partial pressure are disadvantages of electrochemical biosensors based on $\mathrm{O}_{2}$ or $\mathrm{H}_{2} \mathrm{O}_{2}$ detection. The replacement of $\mathrm{O}_{2}$ by PNR is the main advantage of this new reported biosensor assembly, since almost all reported biosensors based on $\mathrm{AlcO}$ x function through hydrogen peroxide (a)

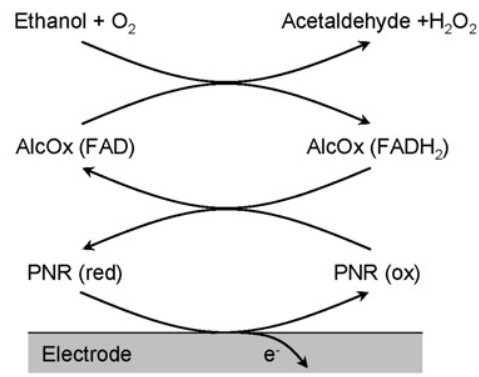

(b)

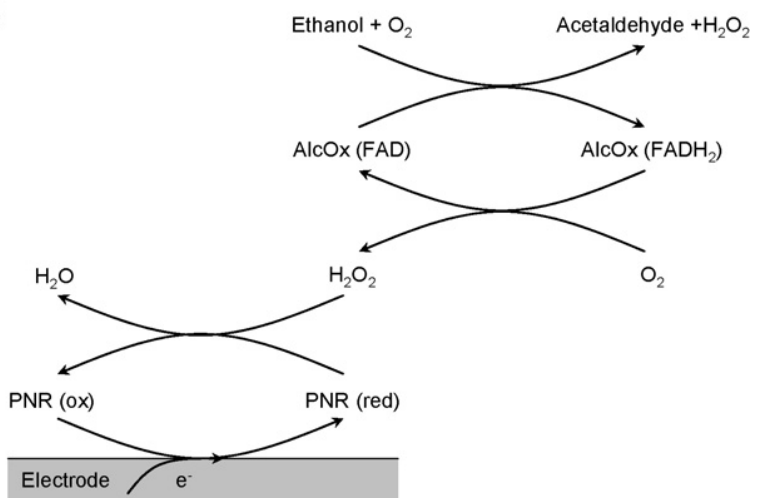

Scheme 1. Proposed reaction mechanism at PNR/AlcOx biosensor at (a) $-0.30 \mathrm{~V}$ vs. SCE (b) applied potentials more negative than $-0.35 \mathrm{~V}$ vs. SCE.

detection. By eliminating the dependence on the presence of $\mathrm{O}_{2}$, the enzymatic reaction is facilitated which improves the sensor performance. As already reported [27], we assume that, in the presence of dissolved oxygen, there is a competition between the oxidation of $\mathrm{FADH}_{2}$ and hydrogen peroxide reduction at the mediator film, see Scheme 1a and b. Thus, the increase of the biosensor response in the absence of dissolved oxygen, which is an anodic change in current, is explained by the absence of the competing reduction reaction of $\mathrm{H}_{2} \mathrm{O}_{2}$, since, presumably, in the absence of $\mathrm{O}_{2}$, no $\mathrm{H}_{2} \mathrm{O}_{2}$ is formed.

A study of the influence of the $\mathrm{pH}$ of the $0.1 \mathrm{M} \mathrm{NaPBS}$ on biosensor response was performed at $-0.30 \mathrm{~V}$ versus SCE. The buffer solution $\mathrm{pH}$ values were chosen in the range of 6-8, since it is known that the $\mathrm{pH}$ of AlcOx extracted from Hansenula sp. is 5.5-8.5 [31]. The results show an increase in the analytical signal up to $\mathrm{pH} 7.5$, above which the signal decreases (Fig. 2). Also, previous studies have shown that the highest enzyme activities and stabilities are achieved at physiological $\mathrm{pH}$ values [16].

In order to find the optimal amount of enzyme within the biosensor membrane, placed on top of the PNR film, three different enzyme solutions were used to construct the biosensor, containing AlcOx in the concentrations at 1,3 and 5\%, as mentioned in Section 2. These biosensors were then used for the amperometric determination of ethanol under the previously optimised conditions. Calibration curves are presented in Fig. 3 and analytical data obtained from analysis of the curves are given in Table 1 . The sensitivity continuously increased with increase in enzyme concentration, by a factor of 5.4 when the 


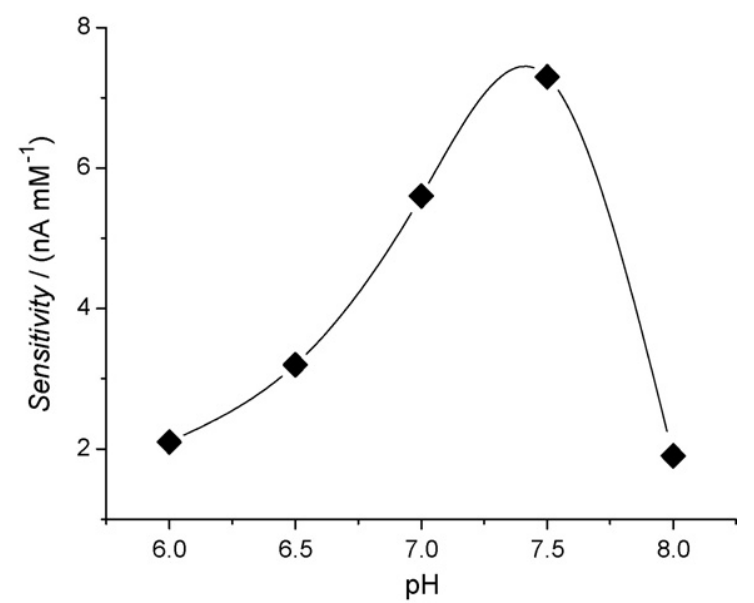

Fig. 2. The influence of buffer $\mathrm{pH}$ on the PNR/AlcOx biosensor sensitivity; measurements performed in $0.1 \mathrm{M} \mathrm{NaPBS}$ by chronoamperometry at $-0.30 \mathrm{~V}$ vs. SCE.

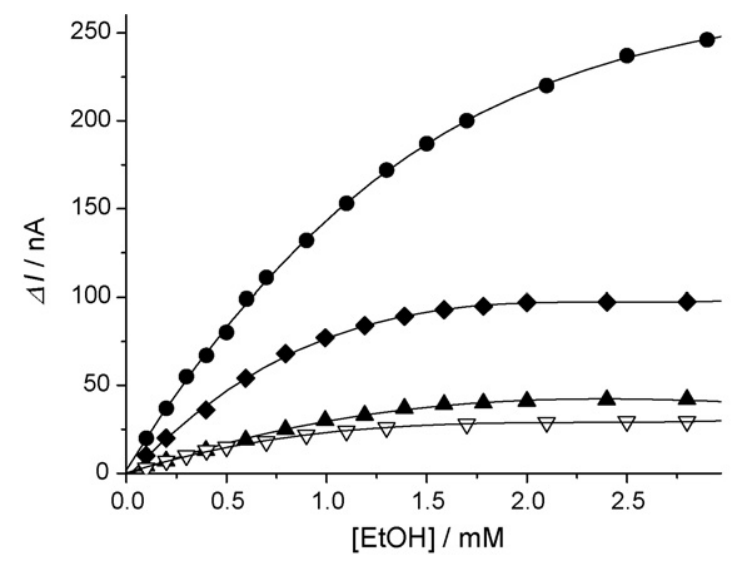

Fig. 3. Calibration curves recorded at AlcOx biosensors at $-0.30 \mathrm{~V}$ vs. SCE in $0.1 \mathrm{M}$ NaPBS pH 7.5: PNR/AlcOx with (४) $1 \%,(\diamond) 3 \%$ and $(\bullet) 5 \%$ AlcOx; $(\nabla) 1 \%$ AlcOx without PNR mediator.

enzyme concentration is increased from $1 \%$ to $5 \%$. However, at the same time, the linear range becomes smaller with an increase in enzyme concentration and the limit of detection changes from $26 \mu \mathrm{M}$ to $44 \mu \mathrm{M}$ (calculated as three times the signal-to-noise ratio). Apparent Michaelis-Menten constants were calculated from Lineweaver-Burk plots. Since the biosensor constructed by using 5\% enzyme solution showed a much higher sensitivity, it was chosen for performing further experiments.

A comparison of the analytical performances of the AlcOx biosensor assembly ( $1 \%$ enzyme concentration), with and without PNR mediator, was done, see Fig. 3. It was observed that using PNR as mediator, the sensitivity increases significantly by a factor of nearly 5 . Additionally, the linear range was extended from $0.4 \mathrm{mM}$ to $0.6 \mathrm{mM}$, and the limit of detection decreased from $45 \mu \mathrm{M}$ to $26 \mu \mathrm{M}$.

\subsection{Analytical properties of the PNR/AlcOx biosensor}

\subsubsection{Reproducibility of the sensor}

In order to examine the reproducibility of the biosensor, the amperometric response to ethanol at three different PNR/AlcOx modified electrodes was recorded under the same experimental conditions. The biosensors showed a linear range up to $0.7 \pm 0.1 \mathrm{mM}$ (R.S.D. $=4.3 \%$ ) and the corresponding detection limit (signal-to-noise-ratio $=3$ ) was $29.7 \pm 1.5 \mu \mathrm{M}$ with a R.S.D. of $5.2 \%(n=3)$. The biosensor sensitivity was $171.8 \pm 14.8 \mathrm{nA} \mathrm{mM}^{-1}$, and a R.S.D. of $8.6 \%$ was obtained. The initial biosensor sensitivity is usually lower when compared with other reported AlcOx-based biosensors [32-34]; nevertheless, stability studies demonstrated a very small decrease of this initial sensitivity value, as will be shown. Most biosensor assemblies based on AlcOx consist in bi-enzyme architectures where, together with the AlcOx, a peroxidase is used for hydrogen peroxide detection at low operating potentials. Redox hydrogels are commonly used for this type of biosensor construction, but since this procedure implies manual mixing of both enzymes together with the cross-linker, problems may appear in the optimisation procedure and reproducibility of these one-layer bi-enzyme biosensors $[35,36]$. The advantages of this newly developed biosensor assembly consist in the simplicity in the construction procedure and good reproducibility (see the analytical parameters above).

Another advantage of these new AlcOx-based biosensors is that they can be used for online measurements in a specially

Table 1

Analytical data obtained from ethanol calibration curves at AlcOx-based biosensors

\begin{tabular}{llllll}
\hline Enzyme (\%) & Linear range $(\mathrm{mM})$ & Sensitivity $\left(\mathrm{nA} \mathrm{mM}^{-1}\right)$ & Correlation coefficient $\left(R^{2}\right)$ & Limit of detection $(\mu \mathrm{M})$ & $K_{\mathrm{M}}^{\text {app }}(\mathrm{mM})$ \\
\hline 1 & $0-1.0$ & 29.2 & 0.999 & 35 & 2.0 \\
3 & $0-0.8$ & 84.0 & 0.999 & 44 & 2.4 \\
5 & $0-0.6$ & 156.3 & 0.999 & 26 & 2.1 \\
\hline
\end{tabular}

Table 2

Analytical data obtained from calibration curves at AlcOx-based biosensors (5\% enzyme concentration) for three different alcohols; experimental conditions as in Fig. 3

\begin{tabular}{lllll}
\hline Aliphatic alcohol & Sensitivity $\left(\mathrm{nA} \mathrm{mM}^{-1}\right)$ & Correlation coefficient $\left(R^{2}\right)$ & Limit of detection $(\mu \mathrm{M})$ & $K_{\mathrm{M}}^{\text {app }}(\mathrm{mM})$ \\
\hline Methanol & 144 & 0.997 & 53 & 2.0 \\
Ethanol & 139 & 0.999 & 25 & 2.1 \\
1-Propanol & 53 & 0.999 & 22 & 2.2 \\
\hline
\end{tabular}




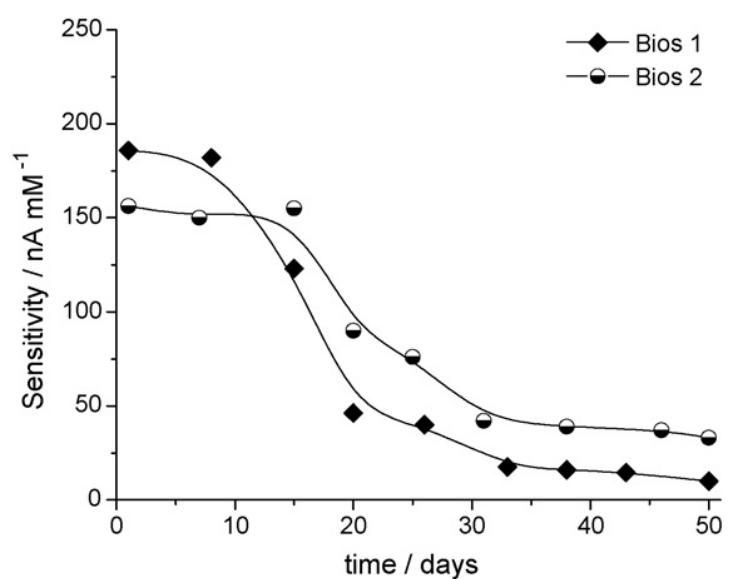

Fig. 4. Operational stability of two different PNR/AlcOx biosensors.

designed cylindrical flow cell, already used for the determination of glucose in flow analysis [26]. Thus, the sensors showed a sufficiently good, reproducible behaviour and can be used for measurements of ethanol.

Kinetic studies of the immobilised enzyme were also carried out. The apparent Michaelis-Menten constant was calculated from the Lineweaver-Burk plots and the value obtained was $1.96 \pm 0.12 \mathrm{mM}$ (R.S.D. $=5.7 \%$ and $n=3$ ).

\subsubsection{Selectivity of the sensor}

Similar experiments were carried out for two other short chain aliphatic alcohols: methanol and 1-propanol and the analytical parameters obtained were compared. Table 2 summarizes the analytical parameters calculated from the calibration curves recorded for each alcohol. As expected, see [8], on increasing the length of aliphatic alcohol chain, the sensitivity of the biosensor decreases while the apparent Michaelis-Menten constant increases.

\subsubsection{Stability of the sensor}

The PNR/AlcOx biosensor was stored in $0.1 \mathrm{M} \mathrm{NaPBS}$ buffer $\mathrm{pH} 7.0$, at $4^{\circ} \mathrm{C}$ when not in use. In order to check the storage stability, a chronoamperogram of the sensor was registered after 6 weeks of storage in the above-mentioned buffer. The sensitivity of the sensor decreased only by about $12 \%$ from the initial value after 6 weeks, which means that the enzyme layer is well attached on the PNR modified electrode.

The operational stability of the enzyme electrode was also tested. For this purpose, calibration curves were recorded three times per week: results are shown in Fig. 4. After 2 weeks of use, biosensor sensitivity decreases by only $0.8 \%$ in the case of one biosensor and by $33.8 \%$ in the case of the other tested biosensor. However, after 50 days of repeated use the sensitivity continues to decrease, maintaining $21.2 \%$ and $5.4 \%$, respectively of the initial sensitivity. This is very promising achievement with respect to the stability of the sensor, since it is well known from previous studies that AlcOx has a poor long-term stability which was the main disadvantage of previous biosensors $[6,8,32]$.
Table 3

Interference of some compounds, molar ratio of 2:1 interferent:ethanol, on the response to ethanol at $\mathrm{PNR} / \mathrm{AlcOx}$ biosensors

\begin{tabular}{lc}
\hline Compound & $\begin{array}{l}\text { Response of the biosensor in the presence of } \\
\text { the interferent compound }\end{array}$ \\
\hline Ascorbic acid & 96.7 \\
Acetic acid & 100.0 \\
Lactic acid & 106.3 \\
Malic acid & 97.5 \\
Oxalic acid & 103.7 \\
Citric acid & 97.3 \\
Tartaric acid & 96.5
\end{tabular}

Table 4

Ethanol analysis in wines

\begin{tabular}{lll}
\hline Wine & \multicolumn{2}{l}{ Ethanol $(\% \mathrm{v} / \mathrm{v})$} \\
\cline { 2 - 3 } & Value declared by the producer & Biosensor \\
\hline Red wine 1 & 12.5 & $13.0 \pm 0.2$ \\
Red wine 2 & 13 & $13.2 \pm 0.1$ \\
White wine & 12 & $12.3 \pm 0.2$ \\
\hline
\end{tabular}

\subsection{Interferences}

There are many easily oxidizable species present in natural samples, the most important of which are ascorbic and tartaric acids, in the case of wine. Since the purpose of this work was to use the biosensors for ethanol determination in wine, a study of interferences from compounds usually present in wine was needed. Several acids were examined as possible interferents that may affect ethanol determination in wine. The high level of selectivity towards common interferences provides the possibility to use this device in clinical, environmental and food control. The results obtained are presented in Table 3. At the PNR/AlcOx biosensor, at $-0.3 \mathrm{~V}$ versus SCE, quite small anodic currents were registered due to the oxidation of lactic acid and oxalic acid. The other acids are reduced at the electrode, but also small currents were recorded, even in the case of ascorbic and tartaric acids, in the presence of which the biosensor response to ethanol decreases by $3.5 \%$ and $3.3 \%$, respectively at a $2: 1$ ratio of interferent:ethanol.

\subsection{Ethanol analysis in natural samples}

The performance of the biosensor for practical applications in the analysis of natural samples was demonstrated by performing the determination of the alcohol content in red and white wines, estimated in terms of ethanol concentration. The samples, as described in Section 2, required only a simple dilution step, in order to fit the linear range of the calibration curve.

The alcohol content of three types of wine was measured and is displayed in Table 4. The biosensor accuracy was assessed by comparison with the results given by the wine producers. 


\section{Conclusions}

Alcohol oxidase from Hansenula sp. has been immobilised by cross-linking with glutaraldehyde in the presence of bovine serum albumin on PNR modified carbon film electrodes. After optimisation of experimental parameters, the biosensor has a detection limit of $30 \mu \mathrm{M}$ and a sensitivity of $172 \mathrm{nA} \mathrm{mM}^{-1}$. The reproducibility is good as well as the operational and storage stability. All these characteristics make the PNR-mediated AlcOx biosensor a good alternative to other determination methods for ethanol in clinical, industry and food analysis.

\section{Acknowledgements}

Financial support from European Project HPRN-CT-200200186 is gratefully acknowledged as well as from Fundação para a Ciência e a Tecnologia (FCT), ICEMS (Research Unit 103). MMB thanks FCT for a PhD grant (SFRH/BD/27864/2006).

\section{References}

[1] G. Schmitt, R. Aderjan, Blutalkohol 41 (2004) 299.

[2] H. Lieden, A.R. Vijayakumar, L. Gorton, G. Marko-Varga, J. Pharm. Biomed. Anal. 17 (1998) 1111.

[3] A.I. Pen'kovskii, A.V. Gusighin, E.I. Federov, R.I. Volkov, M.I. Filatov, R.A. Salina, L.A. Nikolaeva, D.D. Khamelin, V.I. Vereshchagin, Patent Appl.: RU 2001-134083 2001 1213. CAN 141:410165 (2004).

[4] L.V. Shkotova, A.P. Soldatkin, M.V. Gonchar, W. Schuhmann, S.V. Dzyadevych, Mater. Sci. Eng. C 26 (2006) 411.

[5] I.S. Alpeeva, A. Vilkanauskyte, B. Ngounou, E. Csöregi, I.Y. Sakharov, M. Gonchar, W. Schuhmann, Mikrochim. Acta 152 (2005) 21.

[6] O. Smutok, B. Ngounou, H. Pavlishko, G. Gayda, M. Gonchar, W. Schuhmann, Sens. Actuator B: Chem. 113 (2006) 590.

[7] R. Antiochia, I. Lavagnini, Anal. Lett. 39 (2006) 1648.

[8] D. Carelli, D. Centonze, A. De Giglio, M. Quinto, P.G. Zambonin, Anal. Chim. Acta 565 (2006) 27.

[9] K. Svensson, L. Bülow, D. Kriz, M. Krook, Biosens. Bioelectron. 21 (2005) 705 .
[10] J. Razumienè, V. Gurevičienè, A. Vilkanauskytė, L. Marcinkevičienė, I. Bachmatova, R. Meškys, V. Laurinavičius, Sens. Actuator B: Chem. 95 (2003) 378

[11] P. Ozimek, M. Veenhuis, I.J. van der Klei, FEMS Yeast Res. 11 (2005) 975

[12] H.R. Waterham, K.A. Russel, Y. De Vries, J.M. Cregg, Cell Biol. 139 (1997) 1419

[13] S.V. Shleev, G.P. Shumakovich, O.V. Nikitina, O.V. Morozova, H.M. Pavlishko, G.Z. Gayda, M.V. Gonchar, Biochemistry (Moscow) 71 (2006) 245.

[14] T.D. Gibson, J.N. Hulbert, S.M. Parker, Biosens. Bioelectron. 7 (1992) 701

[15] T.D. Gibson, J.N. Hulbert, Anal. Chim. Acta 279 (1993) 185.

[16] A.M. Azevedo, J.M.S. Cabral, D.M.F. Prazer, T.D. Gibson, L.P. Fonseca, J. Mol. Catal. B: Enzym. 27 (2004) 37.

[17] C.M.A. Brett, L. Agnes, H.D. Liess, Electroanalysis 13 (2001) 765.

[18] O.M.S. Filipe, C.M.A. Brett, Electroanalysis 16 (2004) 994.

[19] C. Gouveia-Caridade, C.M.A. Brett, Electroanalysis 17 (2005) 549.

[20] R. Pauliukaite, C.M.A. Brett, Electrochim. Acta 50 (2005) 4973.

[21] M.E. Ghica, C.M.A. Brett, Anal. Lett. 38 (2005) 907.

[22] M. Florescu, C.M.A. Brett, Talanta 65 (2005) 306.

[23] S. De Luca, M. Florescu, M.E. Ghica, A. Lupu, G. Palleschi, C.M.A. Brett, D. Compagnone, Talanta 68 (2005) 171

[24] M.E. Ghica, C.M.A. Brett, Electroanalysis 18 (2006) 748

[25] M.E. Ghica, C.M.A. Brett, Anal. Lett. 39 (2006) 1527.

[26] M.M. Barsan, J. Klinčar, M. Baltič, C.M.A. Brett, Talanta 71 (2007) 1893.

[27] R. Pauliukaite, M.E. Ghica, M.M. Barsan, C.M.A. Brett, J. Solid State Electrochem. 11 (2007) 899.

[28] A.A. Karyakin, E.E. Karyakina, H.L. Schmidt, Electroanalysis 11 (1999) 149.

[29] A.A. Karyakin, O.A. Bobrova, E.E. Karyakina, J. Electroanal. Chem. 399 (1995) 181

[30] J. Greisler, S. Ghisla, P. Kroncek, J. Biochem. 160 (1986) 93.

[31] http://www.sigmaaldrich.com/catalog/search/ProductDetail/SIGMA/A0438.

[32] N.G. Patel, S. Meier, K. Camman, G.C. Chemnitius, Sens. Actuator B: Chem. 75 (2001) 101.

[33] H. Gülce, A. Gülce, M. Kavanoz, H. Coşkun, A. Yildiz, Biosens. Bioelectron. 17 (2002) 517.

[34] F. Mizutani, S. Yaruki, S. Iijiama, Anal. Sci. 13 (1997) 83.

[35] N. Peña, R. Tárrega, A.J. Raviejo, J.M. Pingarrón, Anal. Lett. 35 (2002) 1935.

[36] J. Castillo, S. Gáspár, I. Sakharov, E. Csöregi, Biosens. Bioelectron. 18 (2003) 705 . 